\title{
ChemComm
}

\section{A sulfur mimic of 1,1-bis(diphenylphosphino)methane: a new ligand opens up $\dagger$}

Cite this: Chem. Commun., 2014 50,4707

Received 12th December 2013, Accepted 19th March 2014

DOI: $10.1039 / c 3 c c 49456$

\author{
Peter E. Sues, Alan J. Lough and Robert H. Morris*
}

www.rsc.org/chemcomm

\begin{abstract}
A simple method for synthesizing diphosphine monosulfide species was developed utilizing lithium sulfide and chlorophosphine starting materials. This afforded 1,1,2,2-tetraphenyldiphosphine monosulfide (1), as well as 1,1,2,2-tetracyclohexyldiphosphine monosulfide (2), which could be used as convenient ligand precursors. Upon addition of 1 or 2 to the ruthenium compound $\mathrm{Ru}\left(\mathrm{C}_{5} \mathrm{Me}_{5}\right)(\mathrm{cod}) \mathrm{Cl}$, the diphosphine monosulfides rearranged to give bidentate bis(ditertiaryphosphino)thioether ligands in $\mathrm{Ru}\left(\mathrm{C}_{5} \mathrm{Me}_{5}\right)\left(\mathrm{PPh}_{2} \mathrm{SPPh}_{2}\right) \mathrm{Cl}(3)$ and $\mathrm{Ru}\left(\mathrm{C}_{5} \mathrm{Me}_{5}\right)\left(\mathrm{PCy}_{2} \mathrm{SPCy}_{2}\right) \mathrm{Cl}$ (4).
\end{abstract}

Bidentate phosphorus ligands have been widely employed by inorganic chemists in the synthesis of a large variety of metal complexes. ${ }^{1}$ A particularly noteworthy member of this class of ligands is 1,1-bis(diphenylphosphino)methane (dppm), which has been used, along with its alkyl and aryl substituted analogues, to generate monometallic ${ }^{2}$ and bimetallic (A-frame) compounds, ${ }^{3}$ as well as larger metal clusters. ${ }^{4}$ Moreover, many of these dppm-containing species were found to be active catalysts for hydroformylation and hydrocyanation reactions, as well as other chemical transformations. ${ }^{5-7}$

A related class of ligands is constituted by bis(ditertiaryphosphino)thioethers, which have a sulfur atom replacing the methylene backbone. Typically, synthetic strategies utilizing low temperatures and/or large fluorinated or aliphatic substituents on the phosphorus centres have been employed to stabilize the free thioether species, but despite these efforts, a diphosphine monosulfide byproduct is also commonly seen. ${ }^{8-42}$ In addition, although much has been done in synthesizing and isolating these types of molecules there are few examples of their metal complexes. To our knowledge only Burg et al. and Arnold et al. have reported nickel- ${ }^{25,41}$ and molybdenum-carbonyl ${ }^{22,43}$ complexes, respectively.

Department of Chemistry, University of Toronto, 80 St. George Street, Toronto, Ontario M5S 3H6, Canada. E-mail: rmorris@chem.utoronto.ca

$\dagger$ Electronic supplementary information (ESI) available: Experimental section. Crystal structure and discussion of $\mathbf{1}$. Crystal structure and discussion of S1. Selected bond lengths and angles for $\mathbf{1}, \mathbf{2}, \mathbf{3}, \mathbf{4}$, and $\mathbf{5}$. Crystallographic data tables for compounds 1, 2, 3, 4, 5, and S1. CCDC 976592-976597. For ESI and crystallographic data in CIF or other electronic format see DOI: 10.1039/c3ec49456j
Although bis(ditertiaryphosphino)thioethers superficially resemble dppm, their stability and electronic properties are unlikely to be the same. P-S bonds are chemical analogues of $\mathrm{P}-\mathrm{O}$ bonds and it is known that phosphines and phosphites have drastically different properties. ${ }^{44,45}$ Phosphites are less sigma donating and are more pi acidic, while phosphines have the opposite properties. ${ }^{44}$ Moreover, $\mathrm{P}-\mathrm{C}$ bonds are much more stable than $\mathrm{P}-\mathrm{O}$ bonds, which are sensitive to hydrolysis, alcoholysis, and alkoxide substitution reactions. ${ }^{45}$ As such, bis(ditertiaryphosphino)thioethers may have unique bonding properties that could be useful in tuning the electronic nature of a variety of transition metal catalysts.

In this paper we present a very simple method for synthesizing the previously reported diphosphine monosulfide species 1,1,2,2tetraphenyldiphosphine monosulfide, $\mathbf{1}$, which was formerly synthesized using thiourea and chlorodiphenylphosphine. ${ }^{24,39}$ One equivalent of lithium sulfide was dissolved in acetonitrile, and two equivalents of chlorodiphenylphosphine were added, which afforded 1 as a white powder in high yields (87\%, see Fig. 1). The ${ }^{31} \mathrm{P}\{\mathrm{H}\}$ NMR spectrum of 1 was very diagnostic with two doublets at 42 and $-16 \mathrm{ppm}$ displaying an extremely large $J_{\mathrm{PP}}$ coupling constant of $247 \mathrm{~Hz}$ (in agreement with literature values), indicating the presence of a P-P bond. ${ }^{24,39}$ The structure of $\mathbf{1}$ was also determined by single crystal X-ray diffraction (XRD, see Fig. S1, ESI $\dagger$ ), which matched the results reported by Aluri et al. with a P-P bond length of 2.226(2) $\AA$ and a P-S bond length of 1.953(2) $\AA$ (see Table S1 (ESI $\dagger$ ) for other notable bond lengths and angles). ${ }^{46}$

Using the same synthetic methodology employed in the production of $\mathbf{1}$, an analogous alkyl substituted compound, 1,1,2,2-tetracyclohexyldiphosphine monosulfide, 2 , was generated as

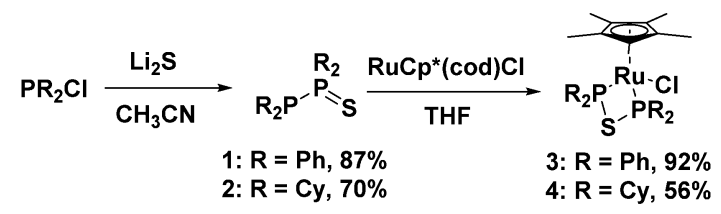

Fig. 1 Synthesis of the monosulfides 1 and 2, as well as ruthenium complexes 3 and $\mathbf{4}$. 


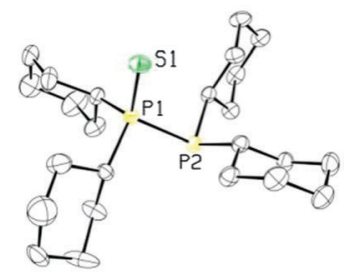

Fig. 2 ORTEP3 representation and atom numbering for 2 (thermal ellipsoids at $50 \%$ probability; all the hydrogens are omitted for clarity).

a white powder in moderate yields (70\%) utilizing chlorodicyclohexylphosphine as a starting material. The ${ }^{31} \mathrm{P}\left\{{ }^{1} \mathrm{H}\right\}$ NMR spectrum of 2 was very similar to that of 1 with two doublets at 59.1 and $-14.0 \mathrm{ppm}$ and a $J_{\mathrm{PP}}$ coupling constant of $302 \mathrm{~Hz}$. The XRD structure of the cyclohexyl-substituted analogue was also similar to that of the phenyl-substituted compound with a P-P bond length of 2.225(4) ^ and a P-S bond length of 1.972(2) $\AA$ (see Fig. 2, and see Table S2 (ESI $\dagger$ ) for other notable bond lengths and angles).

Unexpectedly, given that a chromium complex bearing a 1,1,2,2-tetraphenyldiphosphine monosulfide ligand is known in the literature, ${ }^{47}$ diphosphine monosulfides $\mathbf{1}$ and $\mathbf{2}$ were found to be convenient precursors for metal complexes bearing bis(diphenylphosphino)thioether (dppte) and bis(dicyclohexylphosphino)thioether (dcpte) ligands, respectively. Treatment of $\mathrm{RuCp}^{*}(\mathrm{cod}) \mathrm{Cl}$ (cod = 1,5-cyclooctadiene) with 1,1,2,2-tetraphenyldiphosphine monosulfide generated a neutral ruthenium complex RuCp*$\left(\left(\mathrm{PPh}_{2}\right)_{2} \mathrm{~S}\right) \mathrm{Cl}, 3$, which could be isolated as a yellow powder in excellent yield (92\%, see Fig. 1), while 1,1,2,2-tetracyclohexyldiphosphine monosulfide gave $\mathrm{RuCp}^{*}\left(\left(\mathrm{PCy}_{2}\right)_{2} \mathrm{~S}\right) \mathrm{Cl}$, 4, as a yellow powder in $56 \%$ yield (see Fig. 1). The ${ }^{31} \mathrm{P}\left\{{ }^{1} \mathrm{H}\right\}$ NMR spectrum of 3 and 4 were very informative as only one peak could be seen at $39 \mathrm{ppm}$ and $67 \mathrm{ppm}$, respectively, demonstrating that the inequivalent phosphorus moieties in the initial ligand precursors had become chemically equivalent. In addition, the ruthenium dppte and dcpte species were found to be tolerant of a wide variety of solvents, including acetonitrile, acetone, dichloromethane, methanol, ethanol, and isopropanol. The tolerance to alcohol solvents is of particular interest due to the sensitivity of other P-O and P-S bonds to alcoholysis and alkoxide substitution. ${ }^{45,48}$

A single crystal XRD study showed that 3 displays a piano-stool structure with $\mathrm{Cp}^{*}$ occupying one half of the coordination sphere, while a chloride ligand along with dppte are bound at the other three coordination sites (see Fig. 3a). The bidentate ligand has a $\mathrm{P}(1)-\mathrm{Ru}(1)-\mathrm{P}(2)$ bite angle of $75.8(2)^{\circ}$, which is larger than analogous a)

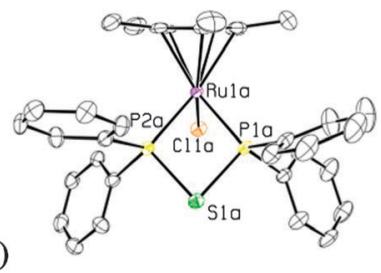

b)

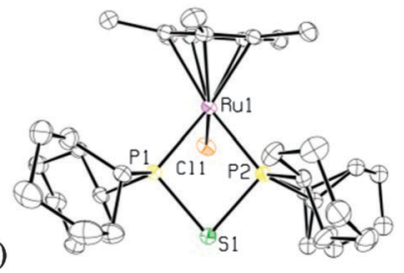

Fig. 3 ORTEP3 representation and atom numbering for (a) $\mathbf{3}$ (thermal ellipsoids at $50 \%$ probability the solvent molecules and all the hydrogens are omitted for clarity); and (b) 4 (thermal ellipsoids at 50\% probability all the hydrogens are omitted for clarity). dppm structures, which have bite angles around $72^{\circ} ., 43$ The $\mathrm{P}(1)-\mathrm{S}(1)-\mathrm{P}(2)$ bond angle is quite acute, $82.1(2)^{\circ}$, which is more compressed than the P-S-P bond angle of $86.9(1)^{\circ}$ found in a monometallic molybdenum carbonyl complex bearing a single dppte ligand (see Table S2 (ESI $\dagger$ ) for other notable bond lengths and angles). ${ }^{43}$ Moreover, the $\mathrm{P}(1)-\mathrm{S}(1)-\mathrm{P}(2)$ bond angle is also significantly smaller than the P-C-P bond angle found in monometallic dppm structures (around $97^{\circ}$ ). ${ }^{2}$

Complex 4 was also characterized by XRD, and displays a similar coordination geometry as complex 3 (see Fig. $3 \mathrm{~b}$ ). The bidentate depte ligand has a $\mathrm{P}(1)-\mathrm{Ru}(1)-\mathrm{P}(2)$ bite angle of $74.71(6)^{\circ}$ and a $\mathrm{P}(1)-\mathrm{S}(1)-\mathrm{P}(2)$ bond angle of $82.19(9)^{\circ}$, which are very similar to the metrical parameters seen for the dppte ligand in 3 . The $P(1)-R u(1)$ and $P(2)-R u(1)$ bond lengths of 2.315(2) and 2.302(2) ^, respectively, however, are longer than the $\mathrm{P}(1)-\mathrm{Ru}(1)$ and $\mathrm{P}(2)-\mathrm{Ru}(1)$ bond lengths of 2.288(4) and 2.278(4) $\AA$, respectively, seen for complex 3 (see Table S3 (ESI $\dagger$ ) for other notable bond lengths and angles). This increase in bond length is most likely caused by the more sterically demanding cyclohexyl substituents, which are pushed away by the $\mathrm{Cp}^{*}$ methyl groups.

Based on our coordination studies we propose that the ligand precursors 1 and 2 exist in equilibrium with their corresponding thioether constitutional isomers in solution (see Fig. 4). Initially, the diphosphinothioether likely forms from an intermediate monophosphine monosulfide species, but the diphosphine monosulfide form is significantly more stable. This drives the equilibrium far to the right, and therefore only $\mathbf{1}$ and $\mathbf{2}$ are seen.

When the $\mathrm{RuCp}^{*}(\operatorname{cod}) \mathrm{Cl}$ complex is introduced into the system, we believe that the diphosphine monosulfides coordinate to the metal first. There is precedent in the literature for this type of structure in the form of the chromium complex discussed previously. ${ }^{47}$ Once coordinated, the diphosphine monosulfide ligands can still interconvert into their thioether isomers and "open up". When this happens, however, the metal centre traps the thioether as a bidentate ligand, and the equilibrium (Fig. 5) is forced to the right. As such, this reaction is likely to be very general and a wide variety of metal precursors should be suitable for this ligand architecture. The most crucial requirement, though, is that the metal has at least one vacant site to facilitate initial coordination of the diphosphine monosulfide precursor, and then the ability to make another site available to trap the thioether species.

Our group has recently reported the synthesis of ruthenium phosphido complexes with bidentate phosphine donors and their reactions with molecular oxygen. ${ }^{49,50}$ In an effort to generate similar phosphido species with a dppte ligand, attempts were made to

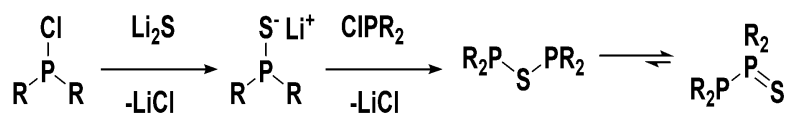

Fig. 4 Proposed mechanism for the formation of 1 and 2.

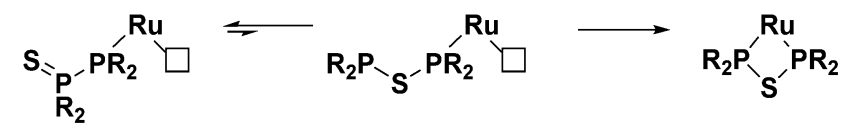

Fig. 5 Proposed mechanism for the formation of $\mathbf{3}$ and $\mathbf{4}$. 
replace the chloride in $\mathbf{3}$ with a secondary phosphine using a synthetic procedure that has been successfully employed for the synthesis of other phosphido products from analogous ruthenium starting materials. ${ }^{49}$ The method utilized stoichiometric amounts of AgOTf as a halogen abstracting agent, but in the dppte case, an excess of AgOTf was necessary to ensure the removal of all of the chloride ligand. This in turn required an excess of diphenylphosphine as the silver cations in solution competed with the ruthenium centre for the monodentate phosphine (see Fig. 6A). Separation of the silver and ruthenium species was not trivial and required several recrystallization steps, which led to unacceptable yields of the target complex (less than 10\%).

In light of these poor results, an alternative synthetic scheme was developed exploiting $\operatorname{RuCp}^{*}(\operatorname{cod}) \mathrm{Cl}$ as the starting material. In the first step, the chloride ligand was abstracted with AgOTf and diphenylphosphine was installed in its place (see Fig. 6B). A ${ }^{31} \mathrm{P}$ NMR spectrum (decoupled) of the reaction mixture revealed two species in solution, at 31.6 and $30.5 \mathrm{ppm}$, both with a large $\mathrm{P}-\mathrm{H}$ coupling, 374 and $347 \mathrm{~Hz}$, respectively. Upon addition of 1, the signal at $31.6 \mathrm{ppm}$ disappeared over time to give a new product, which showed a doublet, and a doublet of doublets at 32.4 and $29.4 \mathrm{ppm}$, respectively, while the other signal persisted in solution along with unreacted $\mathbf{1}$. The signal at $30.5 \mathrm{ppm}$ has since been identified as $\left[\mathrm{RuCp}^{*}\left(\mathrm{HPPh}_{2}\right)_{3}\right][\mathrm{OTf}]$, S1 (see ESI $\dagger$ for a crystal structure of S1 and a more detailed account of the synthesis of 5), which, based on our proposed mechanism for the formation of the bidentate ligand, explains why this species was inert to ligand substitution; the diphosphine monosulfide 1 was unable to displace a diphenylphosphine ligand. The doublet and doublet of doublets, on the other hand, were very diagnostic for the desired product: the doublet represented the equivalent phosphorus nuclei from the bidentate ligand, while the doublet of doublets corresponded to diphenylphosphine, which displayed a strong $\mathrm{P}-\mathrm{H}$ coupling of $356 \mathrm{~Hz}$ (the $\mathrm{P}-\mathrm{H}$ proton was also evident in the ${ }^{1} \mathrm{H}$ NMR). Recrystallization of the reaction mixture allowed for separation of the desired product $\left[\mathrm{RuCp}^{*}\left(\left(\mathrm{PPh}_{2}\right)_{2} \mathrm{~S}\right)\left(\mathrm{HPPh}_{2}\right)\right] \mathrm{OTf}, 5$, in poor yields $(45 \%)$ as a yellow crystalline solid (see Fig. 6).

The XRD structure of 5 revealed a piano-stool structure with the bidentate and diphenylphosphine ligands cis to one another (see Fig. 7). The dppte ligand had a $\mathrm{P}(1)-\mathrm{Ru}(1)-\mathrm{P}(2)$ bite angle of $74.90(6)^{\circ}$, which is smaller than the bite angle seen in 3, but still larger than that of dppm. ${ }^{2}$ The $\mathrm{P}(1)-\mathrm{S}(1)-\mathrm{P}(2)$ bond angle, on the other hand, was found to be $82.46(9)^{\circ}$ in 5 , which is larger than that of 3 , but still much smaller than the

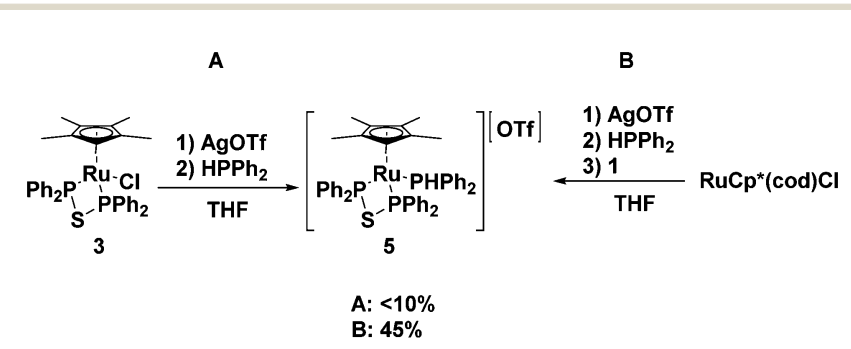

Fig. 6 Two alternative routes to synthesizing complex 5, starting from 3 (left) or RuCp*(cod)Cl (right).

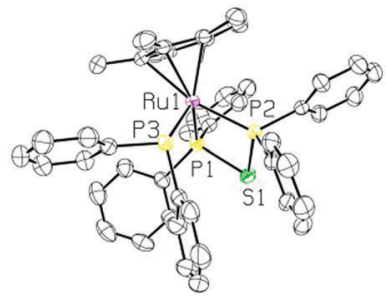

Fig. 7 ORTEP3 representation and atom numbering for 5 (thermal ellipsoids at $50 \%$ probability; the solvent, counter ion and all the hydrogens are omitted for clarity).

molybdenum carbonyl species and monometallic dppm complexes found in the literature (see Table S3 (ESI $\dagger$ ) for other notable bond lengths and angles). ${ }^{2,41}$

It should be noted that the ${ }^{31} \mathrm{P}\left\{{ }^{1} \mathrm{H}\right\}$ NMR spectrum of $\mathbf{5}$ varies significantly depending on the NMR solvent. Both the chemical shift and the $J_{\mathrm{PP}}$ coupling constants change upon moving from deuterated THF to deuterated $\mathrm{MeOH}$. Both sets of signals shift downfield to 36.3 and $34.4 \mathrm{ppm}$ in the more polar solvent, for the doublet of doublets and the doublet, respectively. The $\mathrm{Ph}_{2} \mathrm{PH}$ phosphorus nucleus seems to be more affected by the different solvents, and the doublet of doublet shape becomes more apparent in $\mathrm{MeOH}-d_{4}$ : $J_{\mathrm{PP}}$ changes from 36 and $35 \mathrm{~Hz}$ to 37 and $33 \mathrm{~Hz}$. The diphenylphosphine ligand produces a doublet of doublets rather than a triplet pattern because of residual coupling to the $\mathrm{P}-\mathrm{H}$ proton due to the extremely high $J_{\mathrm{PH}}$ (a decoupling problem).

With 5 in hand, deprotonation of the diphenylphosphine ligand was attempted in THF with an excess of $\mathrm{KH}$. The reaction, however, did not proceed cleanly and did not yield the desired phosphido species. Deprotonation with $\mathrm{KO} t \mathrm{Bu}$ gave even poorer results and resulted in complete decomposition of the ruthenium dppte complex.

We have developed a simple and effective way of preparing alkyl- and aryl-substituted ligand precursors in the form of diphosphine monosulfides, and demonstrated that in the presence of a metal these compounds 'open up' to give the desired bidentate ligand. This valuable discovery makes a previously unattainable class of dppm-like ligands, with varied substituents on the phosphorus donors, readily available, even those thought to be inaccessible due to the instability of the free diphosphinothioether. In addition, we have characterized three metal complexes bearing these ligands and explored their stability with respect to different solvents and basic conditions. It was found that they tolerated a wide range of solvents, but were unstable in the presence of a strong base. More research is needed to explore the chemistry of this underutilized class of ligands.

This work was funded by NSERC Canada as Discovery and RTI grants to RHM.

\section{Notes and references}

1 H. A. Mayer and W. C. Kaska, Chem. Rev., 1994, 94, 1239-1272.

2 R. J. Puddephatt, Chem. Soc. Rev., 1983, 12, 99-127.

3 B. Chaudret, B. Delavaux and R. Poilblanc, Coord. Chem. Rev., 1988, 86, 191-243.

4 S. E. Kabir and G. Hogarth, Coord. Chem. Rev., 2009, 253, 1285-1315. 
5 I. Ojima, C.-Y. Tsai, M. Tzamarioudaki and D. Bonafoux, Organic Reactions, John Wiley \& Sons, Inc., 2004.

6 Z. Freixa and P. W. N. M. van Leeuwen, Dalton Trans., 2003, 1890-1901.

7 P. W. N. M. van Leeuwen, P. C. J. Kamer and J. N. H. Reek, Pure Appl. Chem., 1999, 71, 1443-1452.

8 C. Krawiecki and J. Michalski, J. Chem. Soc., 1960, 881-885.

9 J. B. Lambert, G. F. Jackson and D. C. Mueller, J. Am. Chem. Soc., 1970, 92, 3093-3097.

10 L. Maier, Helv. Chim. Acta, 1962, 45, 2381-2383.

11 L. Maier, J. Inorg. Nucl. Chem., 1962, 24, 275-283.

12 A. Marinetti and F. Mathey, Organometallics, 1982, 1, 1488-1492.

13 H. C. E. McFarlane, W. McFarlane and J. A. Nash, J. Chem. Soc., Dalton Trans., 1980, 240-244.

14 E. N. Ofitserov, O. G. Sinyashin, E. S. Batyeva and A. N. Pudovik, J. Gen. Chem. USSR (Engl. Transl.), 1981, 51, 738-745.

15 A. A. Pinkerton and R. G. Cavell, J. Am. Chem. Soc., 1972, 94, 1870-1874. 16 R. Schmutzler, O. Stelzer and N. Weferling, Chem. Ber., 1988, 121, 391-395.

17 M. Well and R. Schmutzler, Phosphorus, Sulfur Silicon Relat. Elem., 1992, 72, 171-187.

18 H. Westerman, M. Nieger and E. Niecke, Chem. Ber., 1991, 124, 13-16.

19 M. Yoshifuji, K. Shibayama and N. Inamoto, Chem. Lett., 1984, 13, 115-118.

20 E. W. Abel, D. A. Armitage and R. P. Bush, J. Chem. Soc., 1964, 5584-5587.

21 T. Appleby and J. Derek Woollins, Coord. Chem. Rev., 2002, 235, 121-140.

22 D. E. J. Arnold, E. R. Cromie and D. W. H. Rankin, J. Chem. Soc., Dalton Trans., 1977, 1999-2004.

23 D. J. Berg, R. A. Andersen and A. Zalkin, Organometallics, 1988, 7, 1858-1863.

24 P. Bhattacharyya, A. M. Z. Slawin, M. B. Smith, D. J. Williams and J. D. Woollins, J. Chem. Soc., Dalton Trans., 1996, 3647-3651.

25 A. B. Burg and R. A. Sinclair, J. Am. Chem. Soc., 1966, 88, 5354-5355. 26 A. B. Burg and D.-K. Kang, J. Am. Chem. Soc., 1970, 92, 1901-1908.

27 A. B. Burg and K. Gosling, J. Am. Chem. Soc., 1965, 87, 2113-2116.

28 R. G. Cavell and H. J. Emeleus, J. Chem. Soc., 1964, 5825-5832.

29 R. G. Cavell and A. A. Pinkerton, J. Am. Chem. Soc., 1971, 93, $2384-2390$.
30 R. G. Cavell, R. D. Leary, A. R. Sanger and A. J. Tomlinson, Inorg. Chem., 1973, 12, 1374-1380.

31 R. C. Dobbie, L. F. Doty and R. G. Cavell, J. Am. Chem. Soc., 1968, 90, 2015-2020.

32 R. C. Dobbie and M. J. Hopkinson, J. Fluorine Chem., 1974, 3, 367-374.

33 L. F. Doty and R. G. Cavell, Inorg. Chem., 1974, 13, 2722-2729.

34 J. A. S. Duncan, E. A. V. Ebsworth, R. O. Gould, C. L. Jones, D. W. H. Rankin and J. D. Whitelock, J. Chem. Soc., Dalton Trans., 1981, 1028-1033.

35 M. A. El-Hinnawi, E. J. Wucherer, R. Lal De and H. Vahrenkamp, J. Organomet. Chem., 1987, 329, 381-390.

36 V. L. Foss, P. L. Kukhimisterov and I. F. Lutsenko, J. Gen. Chem. USSR (Engl. Transl.), 1982, 52, 1054-1062.

37 K. Gosling and A. B. Burg, J. Am. Chem. Soc., 1968, 90, 2011-2015.

38 G. M. Gray and C. S. Kraihanzel, J. Organomet. Chem., 1982, 238, 209-222.

39 M. Gruber, P. G. Jones and R. Schmutzler, Chem. Ber., 1990, 123, 1313-1317.

40 M. Gruber and R. Schmutzler, Phosphorus, Sulfur Silicon Relat. Elem., 1993, 80, 181-194.

$41 \mathrm{H}$. Einspahr and J. Donohue, Inorg. Chem., 1974, 13, 1839-1843.

42 M. Scheer, F. Uhlig, T. T. Nam, M. Dargatz, H. D. Schädler and E. Herrmann, Z. Anorg. Allg. Chem., 1990, 585, 177-188.

43 F. A. Cotton, L. R. Falvello, M. Tomas, G. M. Gray and C. S. Kraihanzel, Inorg. Chim. Acta, 1984, 82, 129-139.

44 C. A. Tolman, Chem. Rev., 1977, 77, 313-348.

45 P. W. N. M. van Leeuwen, P. C. J. Kamer, C. Claver, O. Pàmies and M. Diéguez, Chem. Rev., 2011, 111, 2077-2118.

46 B. R. Aluri, S. Peitz, A. Wöhl, N. Peulecke, B. H. Müller, A. Spannenberg and U. Rosenthal, Acta Crystallogr., Sect. E: Struct. Rep. Online, 2009, 65, o404.

47 P. G. Jones, A. K. Fischer, M. Farkens and R. Schmutzler, Acta Crystallogr., Sect. E: Struct. Rep. Online, 2002, 58, m478-m479.

48 M. A. Pudovik, L. K. Kibardina, I. A. Aleksandrova, V. K. Khairullin and A. N. Pudovik, J. Gen. Chem. USSR, 1981, 51, 530-538.

49 P. E. Sues, A. J. Lough and R. H. Morris, J. Am. Chem. Soc., 2014, DOI: $10.1021 / \mathrm{ja} 5006724$.

50 P. E. Sues, M. W. Forbes, A. J. Lough and R. H. Morris, Dalton Trans., 2014, 43, 4137-4145. 